\title{
The Health of Paid Caregivers: A Cross-Sectional Study in Spanish Population
}

\author{
Isabel Cuéllar-Flores ${ }^{1}$, Rosa M. Limiñana-Gras ${ }^{2}$, M. Pilar Sánchez-López ${ }^{1}$ \\ ${ }^{1}$ Research Group of Psychological Styles, Gender and Health (EPSY), Red Hygeia (Health \& Gender \\ International Alliance), Complutense University of Madrid, Madrid, Spain \\ ${ }^{2}$ Department of Personality and Psychological Assessment and Treatment, Red Hygeia (Health \& Gender \\ International Alliance), University of Murcia, Murcia, Spain \\ Email: liminana@um.es
}

Received April $8^{\text {th }}, 2013$; revised May $12^{\text {th }}, 2013$; accepted June $10^{\text {th }}, 2013$

\begin{abstract}
Copyright (C) 2013 Isabel Cuéllar-Flores et al. This is an open access article distributed under the Creative Commons Attribution License, which permits unrestricted use, distribution, and reproduction in any medium, provided the original work is properly cited.
\end{abstract}

\begin{abstract}
In countries with a welfare system, such as Spain, paid caregiving is an important profession and investigating the health of people who care for the health of others is becoming an issue of increasing interest. This paper reports on a study assessing the health of people who care for the health of others. It investigates whether caregiving jobs carry with them a higher risk of psychological and physical health problems than other unrelated occupations, and it examines whether risk profiles differ by sex and educational level. A descriptive correlational approach and a cross-sectional design were used. The sample included 330 participants. Half of the participants worked as caregivers, and the other half worked in professions unrelated to caregiving services. The results indicate that paid caregivers have poorer health than their matched counterparts. The variable of caregiving explains this difference better than sex or educational level and professional category.
\end{abstract}

Keywords: Paid Caregivers; Physical Health; Psychological Health; Psychological Stress; Physical Work; Job Satisfaction; Nursing

\section{Introduction}

Investigating the health of people who care for the health of others is becoming an issue of increasing interest. The magnitude of the need for chronic and acute care and the presence of developing welfare states is leading to concern about "caring for the carers". According to the Encuesta sobre Discapacidades, Autonomía personal y situaciones de Dependencia (Spanish survey on disabilities, personal autonomy, and dependency) from the Spanish National Institute of Statistics (INE, 2008), $9 \%$ of the population has some type of disability, and it is estimated that only $12 \%$ of the time devoted annually to caregiving for health reasons is provided by health professionals. The demand for this care will increase in the future (Durán, 2000), as evidenced by the increase in the proportion of health professionals per inhabitant in Spain since the 1990s (INE, 2007). According to the Spanish Active Population Survey (INE, 2007), there were 106,843 nursing assistants and 126,409 nurses in the Spanish health sector in 2006.

Despite these numbers, research on the health of professional or paid caregivers is far less abundant than research on the health of family caregivers. Some of the available data suggest that working in the health sector involves some cost to caregivers. For example, the data on morbidity and mortality among nurses shows that they are at greater risk of dying from cancer, viral hepatitis, falls, suicide, and substance abuse than other professions. Nurses also have increased rates of diabetes and heart disease (National Occupational Mortality Surveillance System, USA, cited by McNeely, 2005). According to the US
Bureau of Labor Statistics, in 2006, nurses working in institutions for the elderly had higher rates of backache, concussions, tendonitis and sprains than the average worker in all private industries (Bureau of Task Statistics [BLS], 2006). Although it seems that the prevalence of disease and lesions varies according to the occupational group under study (Clarke et al., 2002; Edwards \& Burnard, 2003), nursing is usually considered a very stressful occupation with a high prevalence of psychological disorders related to stress (Celentano \& Johnson, 1987; Revicki \& May, 1989).

There are difficulties involved in defining and delimiting the term professional caregiver. This term includes a wide range of categories, from qualified nursing professionals to unqualified home caregivers with no formal regulations to govern their activities. This range partly accounts for the difficulty in identifying the labour and social situation in the caregiving sector. However, there are some indicators of the difficulties faced by these workers. According to the US Bureau of Labor Statistics, in the United States in 2003, caregiving was one of the jobs with the highest rate of pathology; $10.1 \%$ of caregivers working in centres for the elderly and other dependent populations had some kind of pathology. In contrast, the rate of pathology was $6.8 \%$ in the building sector, and $5 \%$ in all other private employment (BLS, 2003). Eriksen (2003a, 2003b, 2006) and Eriksen et al. (2008) have shown that nursing assistants often present backache, a frequent complaint within this occupational group. According to these authors, sleep-related problems, psychological distress, chronic fatigue, and high rates of labour absenteeism are also quite common among nursing assistants. 
Several research publications report a high frequency of distress and other psychological problems among healthcare personnel (Bakker, 2000; Mealer et al., 2009). In fact, most studies have focused on mental health rather than physical health, especially when investigating nurses (McNeely, 2005; Winwood et al., 2006a), although the two factors are complementary. For example, emotional health has been identified as an important and significant predictor of fatigue (Rella et al., 2009). Anxiety, self-perceived satisfaction, and self-esteem have been related to physical health (Hansen, 2003; Stinson et al., 2008), especially among women (Sánchez-López et al., 2006).

Every professional category involves different sources of stress and different health conditions (Foxall et al., 1990; Hardy et al., 1997). Therefore, the kind of job performed is likely to influence workers' health. Comparative studies show that among health care staff, nurses, especially oncologic nurses and nurses working with AIDS patients, run the highest risk of burnout (Bernardi et al., 2005). Although caregiving-related jobs have a variety of specific working conditions (shifts, salary, recognition, etc.), they share certain stress-generating factors, such as a high level of emotional involvement and high responsibility. In fact, health service workers have greater levels of minor psychiatric disorders and fatigue than the general public, and psychiatric morbidity is highest among managers, doctors, nurses and caregivers (Hardy et al., 1997; Wall et al., 1997). Therefore, it is relevant to ask whether paid caregiving, regardless of the level of formal training, the characteristics of the care situation, or the people cared for, involves a stressor that influences physical and psychological health indexes.

In addition, some variables, such as age and female gender, have been suggested as health risk factors in health-related jobs (Chang et al., 2006; Lambert et al., 2004; Wall et al., 1997; Winwood et al., 2006b). In other words, the results of some studies suggest that women working as caregivers and older women have poorer health. It has also been suggested that some professional categories in the caregiving sector incur greater health risks. For example, nursing assistants usually have very low wages, high objective workloads, rather unfavourable labour conditions (rotating night shifts or a lack of contracts), limited training, lack of control over their work, and limited opportunities for job improvement (Mickus et al., 2004). Some studies have associated these factors with greater psychological distress (Eriksen et al., 2003; Hochwälder, 2008).

The present study aims to investigate whether there is a higher risk of psychological and physical health problems in caregiving service occupations than in non-caregiving occupations, and whether risk profiles differ by sex and educational level (related to specific caregiving service professions in Spain).

The objectives of this study are as follows: 1) to analyse whether there are differences in the physical and psychological well-being and health of people working as caregivers and those who work in other fields. Thus, we investigate whether the caregiving factor itself, performed in different conditions, may affect health; and 2) to test whether the variables of sex and educational level modulate health differences between caregivers and non-caregivers. To this end, two subgroups of caregiving professionals were established: those with higher education and those with secondary school or equivalent training only.

Based on the reviewed literature, we proposed the following hypotheses: 1) paid caregivers have worse health than matched non-caregivers in the indexes analysed; 2) caregiving women present worse health than men (whether they work as caregivers or not) and non-caregiving women; 3) caregivers with secondary school education (nursing assistants or geriatric assistants) have worse health than non-caregivers (regardless of their educational level) and caregivers with higher education (such as physicians and nurses).

\section{Methods}

\section{Participants}

Based on data on the prevalence of psychological disorders (Mealer et al., 2009), a sample size of approximately 165 was estimated to achieve $80 \%$ power at a $5 \%$ level of statistical significance. The sample consisted of 330 participants, 60 men $(18.2 \%)$ and 270 women $(81.8 \%)$, half of whom worked as caregivers or health care providers and half of whom worked in areas unrelated to caregiving. The age of the participants ranged from 21 to 66 years, with a mean of 36.65 years $(S D=10.28)$.

The two groups were matched according to the following characteristics: age, sex, educational level, socioeconomic level, marital status and having or not having children. All of the participants had a medium socioeconomic level, $63 \%$ of the participants had a higher education level, and $37 \%$ of the participants had a secondary education level. Of the participants in the sample, $41.5 \%$ were single, $49.3 \%$ were married or partnered, $8.5 \%$ were separated or divorced, and $0.6 \%$ were widowed.

The caregivers worked in centres for the elderly and in hospitals in the Community of Madrid (Spain) in the following areas: nursing $(48.2 \%)$, geriatric or nursing assistant $(37 \%)$, and medical, physiotherapy, psychology, or occupational therapy staff $(14.8 \%)$. The caregivers were contacted in their workplaces and offered the opportunity to participate voluntarily and anonymously in this study.

The participants in the control group worked in different occupations: clerical work $(24.2 \%)$, technicians $(16.4 \%)$, services $(15.8 \%)$, liberal professions $(14.5 \%)$, managers/self-employed $(11.5 \%)$, unskilled workers $(10.3 \%)$ and specialist workers and operators $(7.3 \%)$. The control group participants were contacted at home and were selected from a wider sample of middle-class 1001 participants (as defined by the Spanish National Population Census in the CPN-94 classification and based on the type of work performed (INE, 2001) based on matches to the caregivers for the examined variables.

\section{Design}

This study employed a descriptive correlational approach and a cross-sectional design.

\section{Procedure}

The participants were recruited using two approaches. Caregivers were recruited through contact with several institutions for people with disabilities, and non-caregivers were identified by college students from Universidad Complutense, Madrid, who recruited participants with diverse demographic characteristics (snowball sampling). The data were collected by several trained evaluators during two 45-minute sessions. The sessions took place in the homes or workplaces of the participants from October 2007 to April 2008. All participants were invited to take part in the study following a short description of the nature 
of the study (i.e., "to better understand people's health"). All participants gave their informed consent after the researchers explained the purpose of the investigation, provided a description of the study procedures and alternatives to participation, guaranteed the participants' freedom to withdraw from any part of the study without consequences and guaranteed the anonymity of their data. Based on the total sample, two groups were selected (caregivers and the control group) and randomised into pairs according to the following variables: age (10-year ranges); sex; educational level (two levels: secondary school and higher education); marital status (four categories: single, married or partnered, widow/widower and divorced or separated); and children (two categories: with or without children). All participants were classified as having a mid-range socioeconomic level. The pairing variables were selected to control for their potential confounding effect on the results because they could interact with the selection variables and create differences in the health variables of the participants.

\section{Instruments}

The social and demographic questionnaire included items on age, sex, marital status, educational level, employment status, and profession. Previous research employed this instrument (Sánchez-López et al., 2006; Limiñana, Corbalán, \& SánchezLópez, 2009; Sánchez-López et al., 2008), and satisfactory results were obtained.

A questionnaire on physical health asked participants to indicate their number of chronic diseases, ailments, psychopharmacological medications, frequency of substance consumption (including cigarettes and alcohol), visits to the doctor and selfperceived physical health. This questionnaire was used previously with satisfactory results (Sánchez-López et al., 2006, Sánchez-López et al., 2008).

Psychological health data were obtained from The Rosenberg Self-Esteem Scale (Cronbach's alpha of .88 in Spanish population; see Baños \& Guillén, 2000), the Escala Reducida de Ansiedad (Reduced Anxiety Scale; Martínez-Sánchez et al., 1995; Cronbach's alpha .90 in Spanish population) and the Cuestionario de Satisfacción Autopercibida: laboral, familiar y global (Self-perceived satisfaction questionnaire: work, family, and overall satisfaction). These scales were validated by previous research (see, for example, Díaz-Morales, \& Sánchez-López, 2002; Sánchez-López et al., 2008).

\section{Ethical Considerations}

This study obtained approval from the institutional review board of the Universidad Complutense, Madrid. All participants gave their informed consent after the purpose of the research was explained and the voluntary basis of participation was indicated. The anonymity of the data was ensured.

According to Spanish legislation on the study of human beings (Law 14/2007 of July 3, of biometric research) and based on the Helsinki Declaration, "consent" is defined as the "manifestation of free and conscious will validly emitted by an able person or by his/her authorised representative, preceded by adequate information". In Spain, written and signed informed consent is only applied in biomedical studies (articles 4 and 13 of Law 14/2007).

\section{Data Analysis}

Data were analysed using the statistical software package
SPSS 15.0 for Windows. A multivariate analysis of covariance (MANCOVA) was performed to compare health variables between caregivers and non-caregivers and to explore the modulating effect of sex and educational level on the differences in health variables between caregivers and controls. Being a caregiver, sex and educational level were introduced as independent variables. The dependent variables were related to physical health (number of chronic diseases, number of ailments, number of prescribed drugs taken, frequency of substance consumption, visits to the doctor and self-assessment of physical health) and psychological health (anxiety, self-esteem, work satisfaction, family satisfaction and overall satisfaction). Furthermore, the variable age was introduced into the model as a covariate. Although age was controlled for the independent variable of being a caregiver when pairing participants, it was believed to have a confounding effect on the other two factors (sex and educational level). Before performing the MANCOVA, the normality and homogeneity of variance (Box Test, Levene's test) and the correlation between the dependent variables (Bartlett test of sphericity) were verified. The indexes for the effect size were also calculated using $\eta^{2}$, which indicates the proportion of variance explained by each variation source.

\section{Results}

Table 1 shows the descriptive statistics of the paid caregivers and the control group, classified according to sex and education. In support of Hypothesis 1, the MANCOVA results for the variable being a caregiver [Wilks $(10,280)=.814, p \leq .000, \eta^{2}$ $=.19$ ] confirm that not working as a caregiver has a significant effect on health variables, in this case with a high effect size.

The MANCOVA results for the variable being a caregiver (Table 2) show statistically significant differences in the number of ailments, self-esteem, work satisfaction, family satisfaction, and self-perceived physical health. Caregivers present a greater amount of physical ailments, indicate less self-esteem and family satisfaction and assess their own physical health as worse than their matched control counterparts. However, caregivers are more satisfied with their work than are non-caregivers. The size of these differences is moderate for all variables.

With respect to Hypotheses 2 and 3, the results from the MANCOVA indicate that no statistically significant results were found for sex [Wilks $(10,280)=.968, p \leq .506$ ], educational level [Wilks $(10.280)=.950, p \leq .149$ ], or the being a caregiver* sex interaction [Wilks $(10.280)=.939, p \leq .059$ ].

Although Wilks' lambda for sex and educational level does not have significance below the specified level, in the betweensubjects effects test, a significant effect of the variable sex is found on the number of ailments $[\mathrm{F}(1,289)=4.030, p \leq .046$, $\left.\eta^{2}=.01\right]$ and anxiety $\left[\mathrm{F}(1,289)=3.753, p \leq .054, \eta^{2}=.01\right]$. The estimated values of the comparison indicate that women, whether working as caregivers or not, suffer a greater number of ailments and present greater anxiety than males. Educational level has a significant effect on work satisfaction $[\mathrm{F}(1,289)=$ $\left.3.775, p \leq .053, \eta^{2}=.01\right]$ and number of visits to the doctor $[\mathrm{F}$ $\left.(1,289)=5.494, p \leq .020, \eta^{2}=.01\right]$. The subgroup with a higher educational level shows greater work satisfaction, and the group with a lower educational level shows a greater number of visits to the doctor. The effect size of these differences is small.

However, the results from the MANCOVA indicate a level of significance below the specified level (.05) for the caregiver* 
Table 1.

Descriptive statistics for non-caregivers and caregivers.

\begin{tabular}{|c|c|c|c|c|c|c|c|c|}
\hline \multirow{3}{*}{$\begin{array}{l}\text { Health } \\
\text { Var. }\end{array}$} & \multicolumn{4}{|c|}{ Non-caregivers $(n=165) M(S D)$} & \multicolumn{4}{|c|}{ Caregivers $(n=165) M(S D)$} \\
\hline & \multicolumn{2}{|c|}{ Men $(n=30)$} & \multicolumn{2}{|c|}{ Women $(n=135)$} & \multicolumn{2}{|c|}{ Men $(n=30)$} & \multicolumn{2}{|c|}{ Women $(n=135)$} \\
\hline & $\begin{array}{l}\text { Second Ed. } \\
\quad(n=3)\end{array}$ & $\begin{array}{l}\text { Higher Ed. } \\
\quad(n=27)\end{array}$ & $\begin{array}{l}\text { Second Ed. } \\
\quad(n=72)\end{array}$ & $\begin{array}{l}\text { Higher Ed. } \\
\quad(n=63)\end{array}$ & $\begin{array}{l}\text { Second Ed. } \\
\quad(n=3)\end{array}$ & $\begin{array}{l}\text { Higher Ed. } \\
\quad(n=27)\end{array}$ & $\begin{array}{l}\text { Second Ed. } \\
\quad(n=72)\end{array}$ & $\begin{array}{l}\text { Higher Ed. } \\
\quad(n=63)\end{array}$ \\
\hline 1. & $.0(.0)$ & $.4(.75)$ & $.4(1.2)$ & $.4(1.1)$ & $1.0(1.7)$ & $.1(.3)$ & $.7(1.1)$ & $.4(.8)$ \\
\hline 2. & $13.6(2.3)$ & $13.1(2.8)$ & $16.1(2.9)$ & $15.5(3.2)$ & $17(2.6)$ & $15.6(9.0)$ & $18.5(4.1)$ & $16.5(2.9)$ \\
\hline 3. & $3.7(3.1)$ & $4.5(2.3)$ & $4.4(2.1)$ & $4.1(2.1)$ & $3.3(1.2)$ & $3.8(2.0)$ & $4.2(2.4)$ & $4.3(2.1)$ \\
\hline 4. & $18.3(7.6)$ & 15.7 (9.6) & $21.8(11.6)$ & $22.7(11.6)$ & $21(6.6)$ & $17.5(12.5)$ & $24.3(13.1)$ & $23.9(9.5)$ \\
\hline 5. & $15.7(.6)$ & $15.5(2.4)$ & $15.5(2.5)$ & $15.2(2.0)$ & $10.3(6.4)$ & $13.2(8.4)$ & $10.4(4.4)$ & $10.7(6.9)$ \\
\hline 6. & $3(3.5)$ & $8.2(1.6)$ & $7.1(1.6)$ & $6.8(2.3)$ & $10.0(.0)$ & $8(1.4)$ & $7.8(2.1)$ & $8.2(1.7)$ \\
\hline 7. & $8.7(1.2)$ & $8.5(1.2)$ & $8.4(1.6)$ & $8.1(1.8)$ & $8.7(1.2)$ & $7.3(1.6)$ & $7.4(1.6)$ & $7.7(1.2)$ \\
\hline 8. & $7.3(1.6)$ & $8.5(0.8)$ & $7.9(1.3)$ & $7.7(1.4)$ & $8.3(1.2)$ & $7.8(1.2)$ & $7.6(1.5)$ & $8.0(1.1)$ \\
\hline 9. & $2.3(2.5)$ & $1.8(2.3)$ & $5.1(9.8)$ & $3.5(4.5)$ & $12.3(2.5)$ & $1.4(1.5)$ & $3.0(2.7)$ & $3.2(3.3)$ \\
\hline 10. & $8.7(1.2)$ & $8.0(1.3)$ & $8.0(1.3)$ & $7.9(1.3)$ & $6.7(1.2)$ & $7.8(1.3)$ & $6.9(1.7)$ & $7.7(1.7)$ \\
\hline
\end{tabular}

Note: Health variables: $1=$ Chronic disease, $2=$ Ailment, $3=$ Substance consumption, $4=$ Anxiety, $5=$ Self-esteem, $6=$ Work satisfaction, $7=$ Family satisfaction, $8=$ Overall satisfaction, 9 = Visits to the doctor, 10 = Self-perceived physical health. Abbreviations: Second Ed, Secondary education; Higher Ed, Higher Education.

Table 2.

Multivariate analyses of covariance: non-caregivers versus caregivers.

\begin{tabular}{|c|c|c|c|c|}
\hline Health variables & Non-caregivers $(n=165) M(S D)$ & Caregivers $(n=165) M(S D)$ & $\mathrm{F}(330)^{\mathrm{a}}$ & $\eta^{2}$ \\
\hline 1. Chronic & $.42(1.02)$ & $.47(.87)$ & 1.17 & .004 \\
\hline 2. Ailments & $15.33(3.18)$ & $17.07(4.90)$ & $6.45^{*}$ & .022 \\
\hline 3. Substance consumption & $4.30(2.13)$ & $4.30(2.23)$ & .25 & .001 \\
\hline 4. Anxiety ${ }^{1}$ & $21.10(11.28)$ & $22.82(11.72)$ & .64 & .002 \\
\hline 5. Self-esteem & $15.38(2.28)$ & $11.12(11.26)$ & $17.59^{* * *}$ & .057 \\
\hline 6. Work satisfaction & $7.07(2.05)$ & $8.13(1.83)$ & $26.94^{* * *}$ & .085 \\
\hline 7. Family satisfaction & $8.32(1.62)$ & $7.34(1.64)$ & $3.77^{*}$ & .013 \\
\hline 8. Overall satisfaction & $7.90(1.30)$ & $7.79(1.32)$ & .09 & .000 \\
\hline 9. Visits to the physician & $3.90(7.18)$ & $2.98(3.09)^{\mathrm{a}}$ & 1.94 & .007 \\
\hline 10. Self perceived physical health & $8.01(1.28)$ & $7.46(1.60)$ & $7.861^{* *}$ & .026 \\
\hline
\end{tabular}

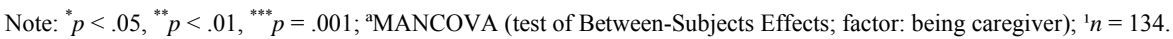

educational level interaction [Wilks $(10,280)=.912, p \leq .003$, $\left.\eta^{2}=.06\right]$ and for the interaction of the three factors caregiver ${ }^{*}$ sex ${ }^{*}$ educational level [Wilks $(10,280)=.895, p \leq .000, \eta^{2}$ $=.10]$. In addition, the MANCOVA shows a significant effect for the covariate age [Wilks $(10,289)=.935, p \leq .041, \eta^{2}$ $=.06]$. The effect size of these differences is moderate.
Multivariate Analyses of Covariance for the caregiver ${ }^{*}$ educational level interaction (Table 3) show a statistically significant, although small, effect on work satisfaction. Post hoc comparisons show that male and female caregivers with secondary education present greater work satisfaction than their colleagues with higher education. However, in the group of non- 
Table 3.

Multivariate analyses of covariance: being caregiver ${ }^{*}$ educational level interaction.

\begin{tabular}{|c|c|c|c|c|c|c|}
\hline \multirow{2}{*}{ Health variables } & \multicolumn{2}{|c|}{ Non-caregivers $(n=165) M(S D)$} & \multicolumn{2}{|c|}{ Caregivers $(n=165) M(S D)$} & \multirow{2}{*}{$\mathrm{F}(330)^{\mathrm{a}}$} & \multirow{2}{*}{$\eta^{2}$} \\
\hline & Sec. Ed. $(n=75)$ & Higher Ed. $(n=90)$ & Sec. Ed. $(n=75)$ & Higher Ed. $(n=90)$ & & \\
\hline 1. Chronic & $.4(1.1)$ & $.4(1.0)$ & $.7(1.1)$ & $.3(.7)$ & 2.99 & .010 \\
\hline 2. Ailments & $16.0(2.9)$ & $14.8(3.3)$ & $18.4(4.0)$ & $16.2(5.6)$ & .35 & .001 \\
\hline 3. Substance consumption & $4.4(2.1)$ & $4.2(2.1)$ & $4.2(2.4)$ & $4.2(2.1)$ & .00 & .000 \\
\hline 4. Anxiety ${ }^{1}$ & $21.7(11.4)$ & $20.6(11.2)$ & $24.1(12.8)$ & $22.0(11.0)$ & .05 & .000 \\
\hline 5. Self-esteem & $15.5(2.5)$ & $15.3(2.1)$ & $10.4(4.4)$ & $11.5(7.4)$ & .75 & .003 \\
\hline 6. Work satisfaction & $6.9(1.9)$ & $7.2(2.2)$ & $8.0(2.1)$ & $8.1(1.6)$ & $14.84^{* * *}$ & .049 \\
\hline 7. Family satisfaction & $8.4(1.6)$ & $8.2(1.6)$ & $7.5(1.6)$ & $7.5(1.4)$ & .29 & .001 \\
\hline 8. Overall satisfaction & $7.9(1.3)$ & $7.9(1.3)$ & $7.6(1.4)$ & $8.0(1.2)$ & .73 & .003 \\
\hline 9. Visits to the physician & $5.0(9.6)$ & $3.0(4.0)$ & $3.5(3.4)$ & $2.6(3.0)$ & 2.80 & .010 \\
\hline 10. Self perceived physical health & $8.1(1.3)$ & $8.0(1.3)$ & $6.9(1.7)$ & $7.7(1.6)$ & 3.59 & .012 \\
\hline
\end{tabular}

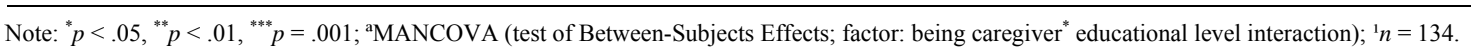

caregivers, greater work satisfaction was found in those with a higher educational level.

Although the Wilks' lambda for caregiver ${ }^{*}$ sex is not significant, the between-subjects effects test shows a statistically significant, although small, effect for the interaction caregiver ${ }^{*}$ sex on work satisfaction $\left[\mathrm{F}(1,289)=7.542, p \leq .006, \eta^{2}=.03\right]$ and number of visits to the doctor $\left[\mathrm{F}(1,289)=5.568, p \leq .019, \eta^{2}\right.$ $=.02]$. In non-caregivers, men show greater work satisfac- tion than women, whereas men and women in the caregiver group have similar levels of satisfaction. Concerning the num- ber of visits to the doctor, male caregivers visit the doctor more often than do male non-caregivers; in contrast, female caregiv- ers go to the doctor less often than non-caregiving females do.

Regarding the caregiver ${ }^{*}$ sex $^{*}$ educational level interaction, a statistically significant effect on work satisfaction was obtained $\left[\mathrm{F}(1,289)=21.295, p<.000, \eta^{2}=.07\right]$, with a moderate effect size. This interaction also has a significant effect on overall satisfaction $\left[\mathrm{F}(1,289)=3.963, p \leq .047, \eta^{2}=.01\right]$ and number of visits to the doctor $\left[\mathrm{F}(1,289)=5.855, p \leq .016, \eta^{2}\right.$ $=.02]$, but the effect size is low.

The male caregivers with secondary education had the highest work satisfaction, followed by male non-caregivers with a higher educational level, and by female caregivers with a higher educational level. Female caregivers with secondary education were next in rank, followed by female non-caregivers with secondary education, female non-caregivers with a higher educational level and, finally, male non-caregivers with secondary education. Regarding overall satisfaction, the ranking from highest to lowest is as follows: male non-caregivers with a higher educational level, male caregivers with secondary education, female caregivers with a higher educational level, female non-caregivers with secondary education, male caregivers with a higher educational level, female non-caregivers with a higher educational level, female caregivers with secondary education and, finally, male non-caregivers with secondary education. Male caregivers with secondary education visited the doctor most often, followed by female non-caregivers with secondary education. These groups were followed by female non- caregivers with a higher educational level, female caregivers with a higher educational level, female caregivers with secondary education, male non-caregivers with secondary education, male non-caregivers with a higher educational level and male caregivers with a higher educational level.

\section{Discussion}

The results support the hypothesis that paid caregiving, regardless of the level of formal training, the characteristics of the situation, and the kind of people cared for, has a consistent negative effect on health, especially physical health. In our study, the caregiver group presented poorer self-perceived physical health and a greater number of ailments than the control group. This finding is in agreement with the results of other studies (Eriksen, 2003a, 2003b, 2006; McNeely, 2005), but it contradicts the results from recent studies such as Winwood et al. (2006a), indicating a greater impact of psychological stress than physical work strain in nursing.

The caregiver group also presented lower self-esteem, which has been considered a predictor of health problems (Stinson et al., 2008). No differences were found concerning the level of anxiety, which contradicts previous findings reporting a high frequency of distress and burn-out symptoms in health personnel (Bakker et al., 2000; Mealer et al., 2009). This finding might be explained by the fact that the type of measurements used in these studies differs from the measurements used in the present work (i.e., previous studies focused on general distress and burn-out symptoms). No differences were found in overall satisfaction, but the caregivers in our study felt more satisfied with their work and less satisfied with their family life than the control group.

These differences in work and family satisfaction could be related to how care is perceived when it is performed in a professional context. Some studies have shown that the perception of caregiving as an emotionally and psychologically rewarding experience is based less on the characteristics of the assistance provided and more on the self-perceived role and responsibility 
and the meaning attributed to the role of the caregiver (Greenberg \& Morris, 1994; Schwartz, 2003). Nevertheless, and despite the higher levels of work satisfaction manifested by the caregivers in this study, the data indicate that caregivers have worse physical health and lower self-esteem, which means that work satisfaction does not seem to offer them protection from health issues.

Our results do not support the hypothesis, based on previous research (Wall et al., 1997), that female caregivers have worse health than do men (whether caregivers or not) and female non-caregivers. The fact of being a woman or a man was only a determinant for modulating the differences in work satisfaction and visits to the doctor between caregivers and non-caregivers, but not in the sense established by the hypothesis. The results of this study indicate that women, in general, present a greater number of ailments and greater anxiety than men, although the effect size is very small. However, female caregivers do not present poorer health than the other three groups. In fact, female caregivers show greater work satisfaction than male and female non-caregivers and have fewer visits to the doctor than female non-caregivers.

It is possible that women, who are used to providing care in the family setting, feel greater acknowledgment and, thus, greater satisfaction in the professional caregiving context. Nevertheless, it is important to bear in mind that the number of men in this study was small. Therefore, potential differences or differential effects on health due to being a woman or a man might not have been detected. However, several studies have shown that when some social and demographic variables are matched in men and women, the differences in physical and psychological health due to sex disappear (Bartley et al., 1998; SánchezLópez et al., 2008) or the size of the differences decreases (Pinqüart \& Sörensen, 2006).

The third hypothesis was not confirmed. This finding suggests that caregivers with secondary education (for example, caregiving assistants) have poorer health than non-caregivers (regardless of their educational level) and caregivers with a higher educational level (physicians, nurses, etc.). Differences were only found in one of the variables, and the results indicate that caregiving professionals with a lower educational level have greater work satisfaction than professionals with higher education, whereas the opposite results were found in the noncaregiver group. According to the results obtained, being a caregiver is more relevant for explaining health characteristics than the specific job category in the caregiving sector. It is possible that controlling for social and demographic variables (by matching participants) in this study had an influence on the results, whereas studies that found differences regarding professional categories (Foxall et al., 1990; Hardy et al., 1997) may not have taken the effect of these variables into account.

Nevertheless, when the interaction between the three factors (being a caregiver, sex and educational level) is analysed, the situation is different because differences were found in three of the health variables under study. Therefore, it seems necessary to include both variables (educational level and sex) to better understand the characteristics of care-related professions.

\section{Study Limitations and Implications}

We note several limitations of the current study. This research should be replicated in the future with populations of different nationalities to continue to verify its generalisability.
Another limitation of this study is the use of self-reported measures. It is necessary to utilise objective health indicators to complete the investigation of caregiving and health. Although the proportion of females to males in this study reflects the real-life situation (INE, 2007b), the presence of such a small number of men is a limitation. A sample with a greater number of paid caregivers, especially men, is required for an in-depth study to confirm the combined modulating effect of sex and educational level (or professional category) on the results.

Being a caregiver per se is more important than the professional category for health and satisfaction. Based on the data obtained in this study, it would be interesting to design studies of social and organisational characteristics and other moderating factors associated with different occupational groups and to test whether these characteristics are responsible for the differences between professionals in health and satisfaction.

Other variables that were not included in this work, such as the level of depression, classic burn-out measurements and objective measures, should be part of future research on the health of caregivers.

\section{Conclusion}

Paid caregiving, regardless of the level of formal training, the characteristics of the situation, and the kind of people cared for, is related to a negative effect on physical health. The caregivers presented lower self-esteem as well as greater satisfaction with their work and less satisfaction with their family life.

Caregivers, whether nursing, medical staff, physiotherapy, psychology, or occupational therapy staff, perform a crucial role in the functioning of social and health service institutions. Therefore, it is even more necessary that they receive attention in research focused on health. The results of this study show that both caregivers and those for whom they care have a need for care and attention to secure the welfare of both groups and the smooth operation of services. This knowledge is potentially useful in health programs and socio-health policies, and it reveals the need to systematically introduce the study of caregivers to health-related investigations and interventions to facilitate the diagnosis and prevention of poor health.

\section{REFERENCES}

Bakker, A. B., Killmer, C. H., Siegrist, J., \& Schaufeli, W. B. (2000). Effort-reward imbalance and burnout among nurses. Journal of Advanced Nursing, 31, 884-891. doi:10.1046/j.1365-2648.2000.01361.x

Baños, R., \& Guillén, V. (2000). Psychometric characteristics in normal and social phobic samples for a Spanish version of the Rosemberg self-esteem scale. Psychological Reports, 87, 269-274.

Bartley, M., Davey Smith, G., \& Blaine, D. (1998). Beyond the black report. Sociology of Health and Illness, 20, 563-577. doi:10.1111/1467-9566.00119

Bernardi, M., Catania, G., \& Marceca, F. (2005). The world of nursing burnout. A literature review. Professioni Infermieristiche, 58, 75-79.

BLS, Bureau of Labor Statistics $(2003,2006)$. Work-related injury and illness statistics by industry. www.bls.gov

Celentano, D. D., \& Johnson, J. V. (1987). Stress in health care workers. Occupational Medicine, 2, 593-608.

Chang, E., Daly, J., Hancock, K., Bidewell, J., Johnson, A., Lambert, V., \& Lambert, C. (2006). The relationships among workplace stresssors, coping methods, demographic characteristics and health in Australian nurses. Journal of Proffesional Nursing, 22, 30-38. doi:10.1016/j.profnurs.2005.12.002

Clarke, S., Rockett, J., Sloane, D., \& Aiken, L. (2002). Organizational 
climate, staffing, and safety equipment as predictors of needlestick injuries and near-misses in hospital nurses. American Journal of Infection Control, 30, 207-216. doi:10.1067/mic.2002.123392

Díaz-Morales, J. F., \& Sánchez-López, M. P. (2002). Connections between personality types and self-perceived satisfaction in several life areas in University students. Psichotema, 14, 100-105.

Durán, M. A. (2000). New division of labour in health care. Política y Sociedad, 35, 9-30.

Edwards, D., \& Burnard, P. (2003). A systematic review of stress and stress management interventions for mental health nurses. Journal of Advanced Nursing, 42, 169-200. doi:10.1046/j.1365-2648.2003.02600.x

Eriksen, W. (2003a). The prevalence of musculoskeletal pain in Norwegian nurses' aides. International Archives of Occupational and Environmental Health, 76, 625-630. doi:10.1007/s00420-003-0453-6

Eriksen, W. (2003b). Service sector and perceived social support at work in Norwegian nurses' aides. International Archives of Occupational and Environmental Health, 76, 549-552. doi:10.1007/s00420-003-0447-4

Eriksen, W., Bruusgaard, D., \& Knardahl, S. (2003). Work factors as predictors of sickness absence: A three month prospective study of nurses' aides. Occupational and Environmental Medicine, 60, 271278. doi:10.1136/oem.60.4.271

Eriksen, W. (2006). Work factors as predictors of persistent fatigue: A prospective study of nurses' aides. Occupational and Environmental Medicine, 63, 428-434. doi:10.1136/oem.2005.019729

Eriksen, W., Bjorvatn, B., Bruusgaard, D., \& Knardahl, S. (2008). Work factors as predictors of poor sleep in nurses' aides. International Archives of Occupational and Environmental Health, 81, 301-310. doi:10.1007/s00420-007-0214-Z

Foxall, M. J., Zimmerman, L., Standley, R., \& Bene-Captain, B. (1990). A comparison of frequency and sources of nursing job stress perceived by intensive care, hospice and medical-surgical nurses. Journal of Advanced Nursing, 15, 577-584.

doi:10.1111/j.1365-2648.1990.tb01857.x

Greenberg, M., \& Morris, N. (1994) Engrossment: The newborn's impact upon the father. American Journal of Orthopsychiatry, 44, 520531. doi:10.1111/j.1939-0025.1974.tb00906.x

Hansen, S. (2003). Mental health issues associated with cardiovascular disease in women. Psychiatric clinics of North America, 26, 693-712. doi:10.1016/S0193-953X(03)00037-6

Hardy, G. E., Shapiro, D. A., \& Borrill, C. S. (1997) Fatigue in the workforce of national health service trusts: Levels of symptomatology and links with minor psychiatric disorder, demographic, occupational and work role factors. Journal of Psychosomatic Research, 43, 83-92. doi:10.1016/S0022-3999(97)00019-6

Hochwälder, J. (2008). A longitudinal study of the relationship between empowerment and burnout among registered and assistant nurses. Work: A Journal of Prevention, Assessment and Rehabilitation, 30, 343-352.

INE Instituto Nacional de Estadística (2001). Population and housing census. www.ine.es

INE Instituto Nacional de Estadística (2007). Working population survey. Registered health professionals. www.ine.es

INE Instituto Nacional de Estadística (2008). Survey on disabilities, self-autonomy, \& dependence situations. www.ine.es

Lambert, V., Lambert, C., Itano, J., Inouye, J., Kim, S., Kuniviktikul, W., Sitthimongkol, Y., Pongthavornkamol, K., Gasemgitvattana, S., $\&$ Ito, M. (2004) Cross-cultural comparison of workplace stressors, ways of coping and demographic characteristics as predictors of physical and mental health among hospital nurses in Japan, Thailand, South Korea and the USA (Hawaii). International Journal of Nurs- ing Studies, 41, 671-684. doi:10.1016/j.ijnurstu.2004.02.003

Limiñana, R., Corbalán, F. J., \& Sánchez-López, M. P. (2009). Thinking styles and coping when caring for a child with severe spina bifida. Journal of Developmental and Physical Disabilities, 19, 125-134.

Martínez-Sánchez, F., Cano-Vindel, A., Castillo, J. C., Sánchez, J. A., Ortiz, B., \& Gordillo, E. (1995). A reduced anxiety scale based on the anxiety situations and responses inventory. Anales de psicología, $11,97-104$

Mealer, M., Burnham, E. L., Goode, C. J., Rothbaum, B., \& Moss, M. (2009). The prevalence and impact of post traumatic stress disorder and burnout syndrome in nurses. Depression and Anxiety, 26, 11181126. doi:10.1002/da.20631

McNeely, E. (2005). The consequences of job stress for nurses' health: Time for a check-up. Nursing Outlook, 53, 291-299. doi:10.1016/j.outlook.2005.10.001

Mickus, M., Luz, C., \& Hogan, A. (2004). Voices from the front: Recruitment and retention of direct care workers in long term care across Michigan. Lansing, MI: Michigan State University.

Pinqüart, M., \& Sörensen, S. (2006). Gender differences in caregiver stressors, social resources, and health: An updated meta-analysis. Journals of Gerontology, Series B: Psychological Sciences and Social Sciences, 61B, 33-45. doi:10.1093/geronb/61.1.P33

Rella, S., Winwood, P., \& Lushington, K. (2009). When does nursing burnout begin? An investigation of the fatigue experience of Australian nursing students. Journal of Nursing Management, 17, 886-897. doi:10.1111/j.1365-2834.2008.00883.x

Revicki, D. A., \& May, H. J. (1989). Organizational characteristics. occupational stress, and mental health in nurses. Behavioral Medicine, 15, 30-36. doi:10.1080/08964289.1989.9935149

Sánchez-López, M. P., Aparicio-García, M. E., \& Dresch, V. (2006). Anxiety, self-esteem and self-perceived wellbeing: Differences between men and women. Psicothema, 18, 584-590.

Sánchez-López, M. P., López-García, J. J., Dresch, V., \& Corbalán, J. (2008) Sociodemographic, psychological and health-related factors associated with poor mental health in Spanish women and men in midlife. Women, \& Health, 48, 445-465. doi: $10.1080 / 03630240802575096$

Schwartz, Ch. (2003) Parent of children with chronic disabilities: The gratification of caregiving. Families in Society, 84, 576-584. doi:10.1606/1044-3894.143

Stinson, D. A., Logel, C., Zanna, M. P., Holmes, J. G., Cameron, J. J., Wood, J. V., \& Spencer, S. J. (2008) The cost of lower self-esteem: Testing a self- and social-bonds model of health. Journal of Personality and Social Psychology, 94, 412-428. doi: 10.1037/0022-3514.94.3.412

Wall, T. D., Bolden, R. I., Borrill, C. S., Carter, A. J., Golya, D. A., Hardy, G. E., Haynes, C. E., Rick, J. E., Shapiro, D. A., \& West, M. A. (1997). Minor psychiatric disorder in NHS trust staff: Occupational and gender differences. British Journal of Psychiatry, 171, 519-523. doi:10.1192/bjp.171.6.519

Winwood, P., Lushington, K., \& Winefield, A. H. (2006a) Disentangling the effects of psychological and physical work demands on sleep and recovery within a sample of Australian nurses. Journal of Advanced Nursing, 56, 679-689. doi:10.1111/j.1365-2648.2006.04055.x

Winwood, P. C., Lushington, K., \& Winefield, A. H. (2006b). The contribution of age, domestic responsibilities and shiftwork to work-related fatigue and recovery within a sample of full-time Australian nurses. Journal of Advanced Nursing, 56, 438-449. doi:10.1111/j.1365-2648.2006.04011.x 